\title{
ECC
}

\section{Quantum study of solvent effect with POPC phospholipid bilayers in a cell membrane and its impact on active and targeted drug delivery}

\author{
Akbar Elsagh \\ Faculty of Chemistry, Department of Chemistry, North Tehran Branch, Islamic Azad University, \\ Tehran, Iran
}

Received: 04 August 2019, Accepted: 05 November 2019, Published: 12 December 2019

\begin{abstract}
In this study, since the system was relatively large, the modified methods of molecular mechanics and quantum mechanics were used to obtain changes in the thickness of the membrane phospholipids by different solvents. Thus, according to the theory of fluidity Mosaic, the changes that were made due to various solutions and, consequently, the constant change of solution dielectric effect on the thickness of the phospholipid membrane. By comparing these changes, it was found that changes in the width of the inner layers in the vicinity of different solvents, with the shift from this effect, are consistent with the total width of the phospholipid membrane. It seems to be the determining factor in changing the width of the diaphragm against different solvents of the phospholipid inner layer. Accordingly, the depth of membrane thinning was calculated for each solvent in comparison with the water solution, which was reduced by decreasing the solvent dielectric constant, thinning of the solution and the phospholipid membrane, respectively. Thermodynamic functions for the usual solution were calculated using frequency studies and thermodynamic relations. These functions indicate that the system is stable in terms of thermodynamics and stabilizes the desired solution without distorting structural integrity. Hence, these structures can be used as agents for the delivery, exchange, and absorption of materials. The membrane structures studied in this study are used in the mechanism, and drug delivery interactions in the body and the pharmaceutical industry as a channel for the delivery and exchange, and these results can be used in the discussion of intelligent redeploy of drugs and Nano drug. So, paying attention to the operating environment and the thinning factor and the thickness of the membrane increase the reactivity, improve the solubility and delivery of drugs, reduce the dose of the medicine and increase its effectiveness.
\end{abstract}

Keywords: Computational chemistry; phospholipid; thinning factor; medication transfer.

\section{Introduction}

The importance of membrane phospholipids is very clear for the effective and targeted delivery of drugs materials from within the cell membrane. Among the biological reactions of living organisms and enzymatic reactions, the responses of membrane phospholipids

*Corresponding author: Akbar Elsagh

Tel: +98 (21) 88971522, Fax: +98 (21) 88971522

Eurasian Chem. Commun. (2020) 440-455

E-mail: akbarelsagh@gmail.com 
can be mentioned [1]. Phospholipids are one of the most essential polar lipids that are the main constituents of the cell membrane of all living organisms [2-5]. Phospholipids act by forming a duallayer, such as a protective and selective barrier, and regulate cell life [6,7]. Considering the importance of membrane phospholipids and its various applications in various fields of science and industry, including chemical sensors, pharmaceutical, cosmetic and pharmaceutical fields, pharmaceuticals, and chemistry, biochemistry and medicine, we use a QM/MM method to study quantum effects solvent on the thickness of membrane phospholipids $[8,9]$. Computational chemistry includes molecular modeling, computational methods, and molecular design by computer, as well as chemical data and configuration of material synthesis $[6,10]$. Computational chemistry is instrumental in cases where it is difficult to understand a chemical process or information about procedures that are difficult to see and do in the laboratory [11]. Most chemical reactions occur in the soluble phase, and the water solvent is the chemical bedding agent as the natural solvent for the chemical bedrock. Solubility in pharmaceutical production is significant in the pharmaceutical industry. Of course, most medications do not have much water solubility. Any change in the state and type of solvent can change the process of solubility and chemical reactions [12]. This research relies on the structure of membrane phospholipids and its physics and quantum chemistry changes versus solvent in the transition from the classic model to the quantum model. Therefore, in this research, we try to study the above process and the resulting changes. Considering the importance of the issue in recent years, the quantum mechanical study of biochemical and biological processes [13-18] and the behavior of lipid bilayer membranes [19-22] have been the subject of much research.

\section{Computational methods}

By computing, molecular and quantum mechanics, the structure of the phospholipid membrane was simulated and optimized [21,23]. Then, by quantum computation [24], the effects of solvent on the thickness of membrane phospholipids were calculated.

\section{Simulation and optimization of phospholipid structure}

The Chem3D software simulated the structure of phospholipid, and the resulting structures were geometrically optimized [25]. Then, the HyperChem program was executed in the drop-down table and periodic box was selected, then, in the predefined right window, the program presented a default option based on three components $\mathrm{x}, \mathrm{y}, \mathrm{z}$, respectively, in the length and width and height of the area which the solvent molecules occupy, i.e. the lowest dimensionality of the solvent medium [23].

Figures 1 and 2, respectively, illustrate the simulated image of a single phospholipid molecule (POPC) in a membrane and simulated phospholipid area about three spatial configurations in the Monte Carlo simulation [26,27]. 


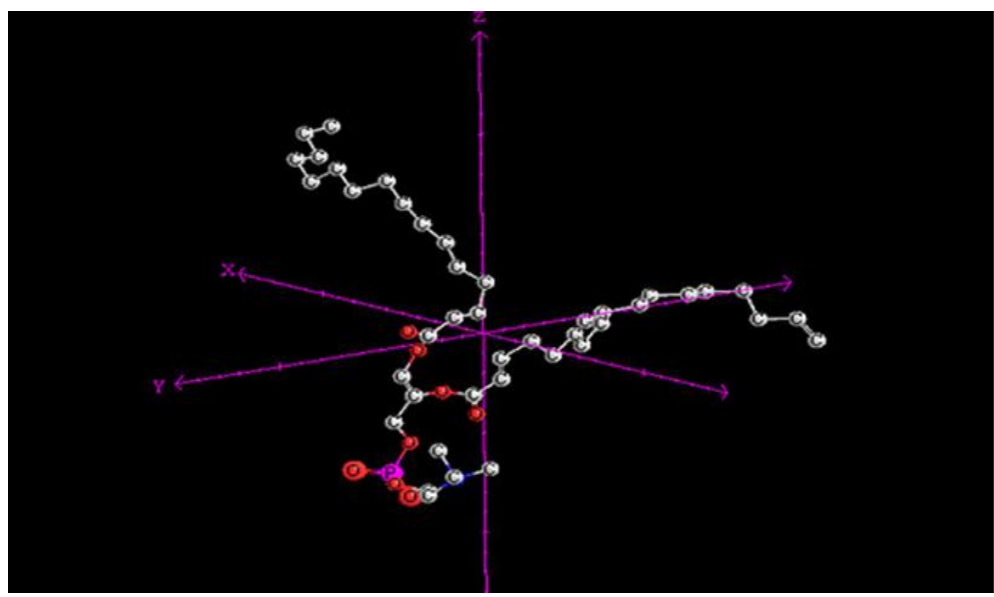

Figure 1. The simulated phospholipid molecule (POPC) compared to three spatial variants in the Monte Carlo simulation

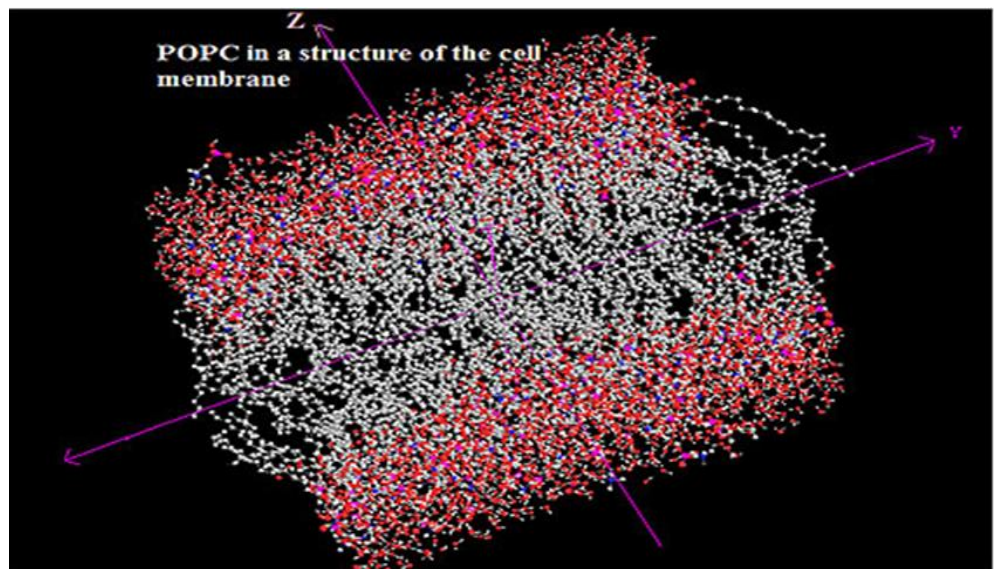

Figure 2. The POPC simulated structure compared to three spatial variants in the Monte Carlo simulation

Regarding the length of the phospholipid, a volume of solvent molecules was chosen, with the lowest number of solvent molecules and the highest interactions between solvent molecules and the structure. By default, the water molecules are placed in the box. The blue environment has the highest dielectric constant and is equal to 78.30. After creating the solvent environment in HyperChem, we save it with the ENT extension. Note that when you save two options, Hydrogens and connectivity are enabled. In this program, $\mathrm{H}_{2} \mathrm{O}$ molecules can easily be converted to other molecules [28].
Confirmation of the simulation of the phospholipid structure

The phospholipid structure is optimized at the HF surface with the base series 6$31 \mathrm{G}$, and after drawing Chem3D, Gaussian input was prepared.

\section{Hamiltonian kinetic electron density for POPC}

As shown in Figure 3, two light points represent the two branches of phospholipid hydrocarbons. Based on the location and status of these two phosphoric acid hydrocarbon branches, it is possible to determine the spatial position about other peaks in shape. The Sharp graph also shows where the molecule is more sensitive to electron density. 


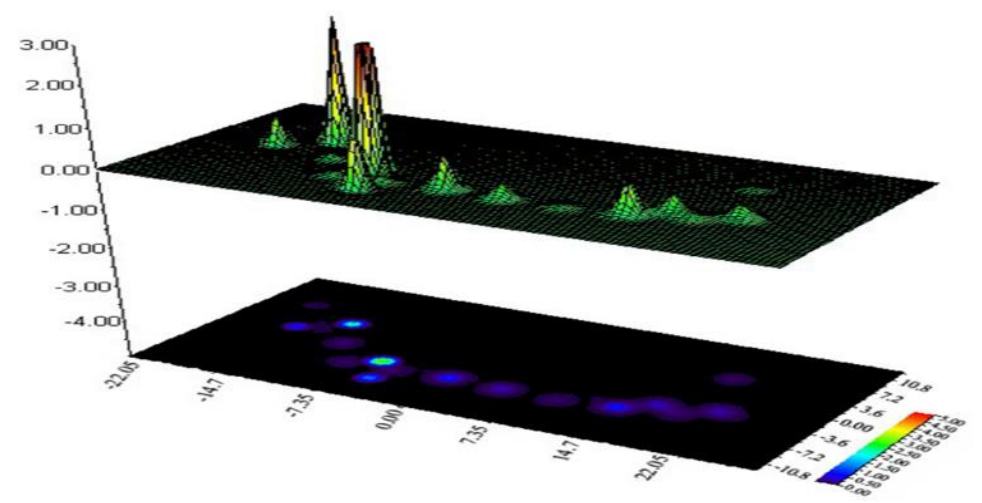

Figure 3. Hamiltonian electron density for POPC

The vector field map with contour lines for phospholipid hydrocarbon structures

According to the results obtained in Figure 4, as shown, two phospholipid hydrocarbon species are known. Of course, it is evident that in addition to phospholipid hydrocarbon branches, other groups also have loud and distinct spectra in shape. In terms of qualitative comparison, these results and frequencies can be used.

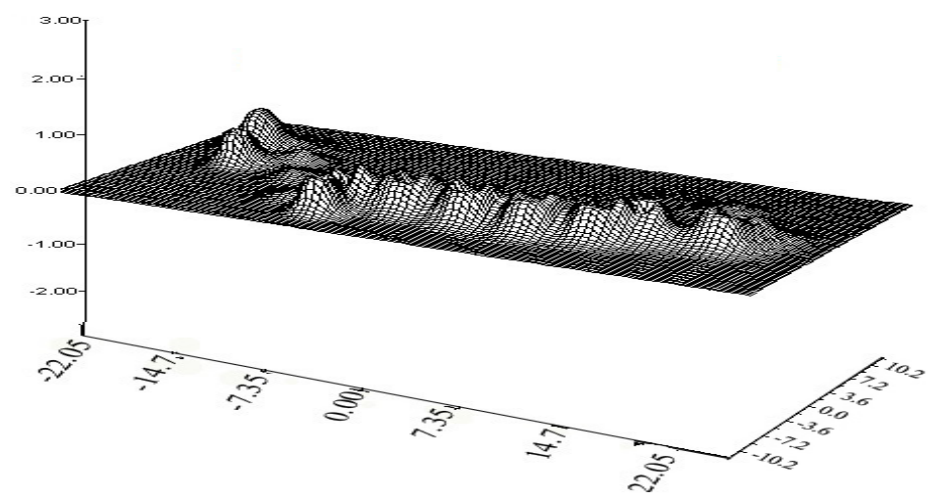

Figure 4. Vector map with of the contour lines for POPC

\section{Color field map for the POPC}

By examining Figure 5, we find that one of the branches of phospholipid hydrocarbons is not visible. The reason for this an eclipse-like phenomenon, where one of the phospholipid hydrocarbon branches is overshadowed and can't be seen, and only the other branch can be observed. However, it is still possible to detect the position of the membrane by the same information.

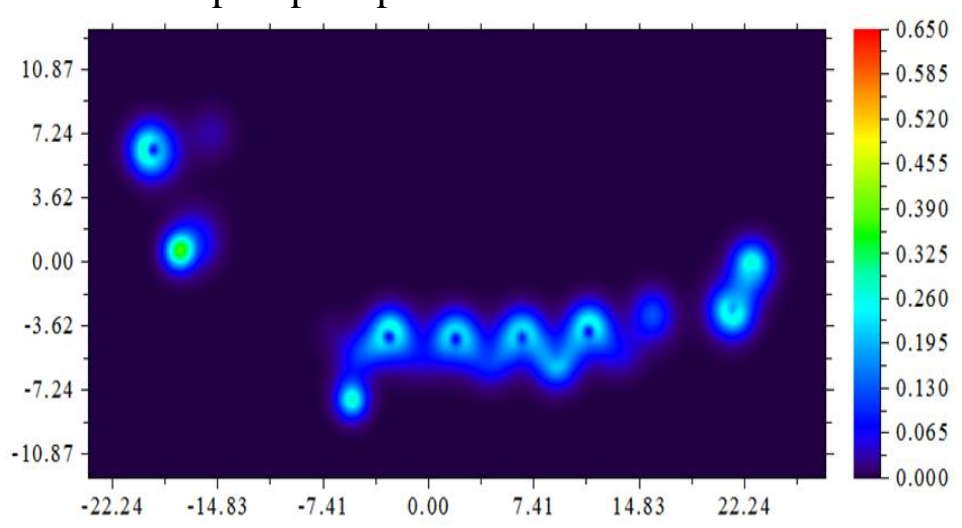

Figure 5. Contour map of density state for POPC 
The contour line map of electron density for POPC

Figures 6 and 7 show that electron densities are properly distributed to their
POPC electron density relative to their spatial position and are validating each other.

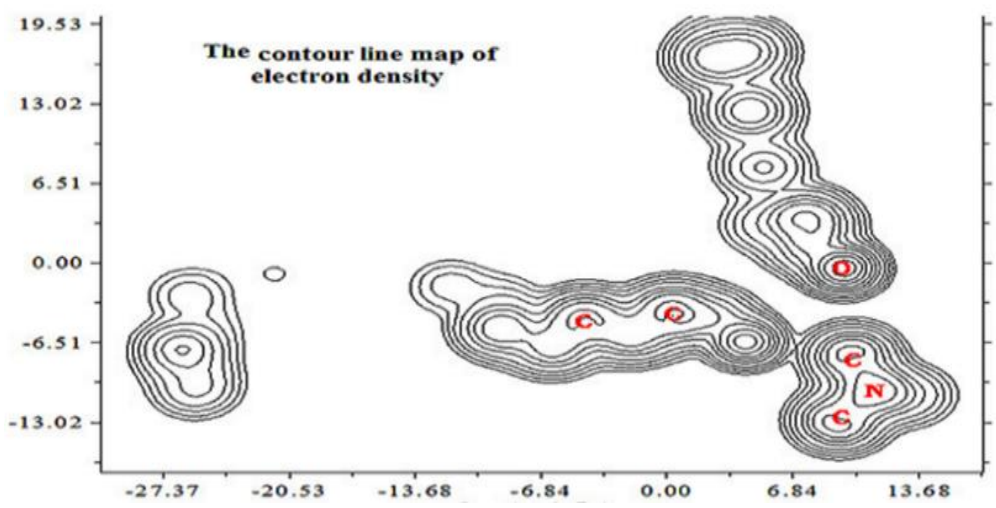

Figure 6. The contour line map of electron density for POPC phospholipids

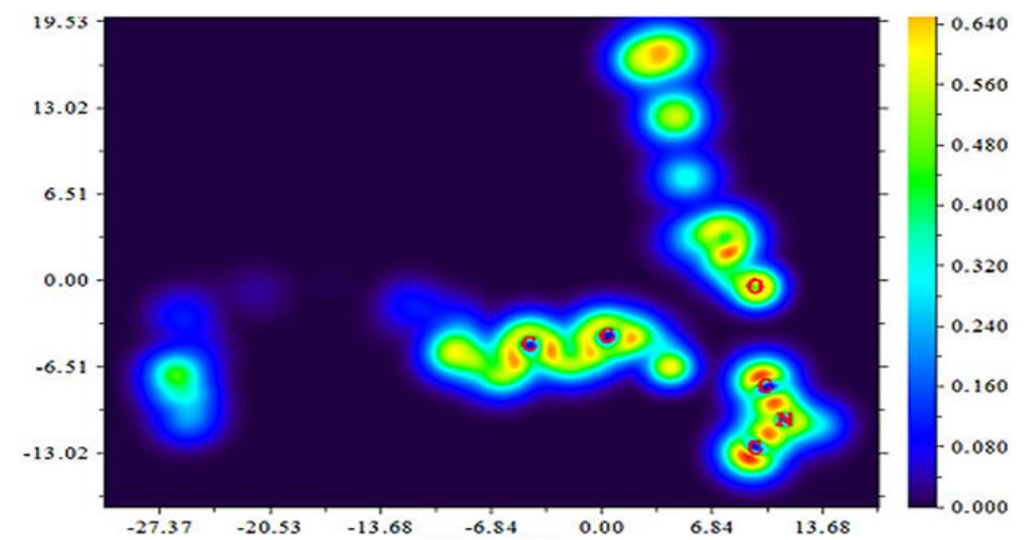

Figure 7. Color field map for the Localized orbital locator (LOL) for POPC

In Figure 8, the position of phosphorus orange, atom 7, 9, 10, 11, phospholipid atoms has been shown to 14, 16 and 33; in addition, 35 oxygen is have atom 4 nitrogen in blue, atom 8 red and all the gray atoms are carbon.

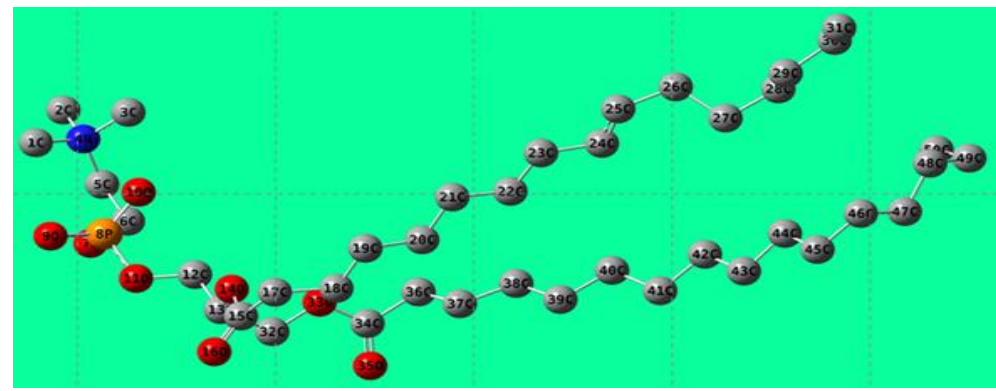

Figure 8. Formation of phospholipid molecule atoms (POPC)
Phospholipid
and membrane dynamics (Fluid mosaic model)
The cell membrane has a single structural unit; if the proteins are set apart from it, a unique structure is obtained from the association of lipid-protein in the
membrane, known as the fluid mosaic model. In a fluid mosaic model, proteins are isolated proteins that penetrate two layers of lipids- that is, proteins in membranes that are like mosaics. The phospholipid membranes adhere to this 
theory of mosaic fluidity and have a dynamic state [22].

That is, based on the membrane dynamics, the thickness of the membrane is not constant and is affected by the external and internal environments, in particular, solvent and solvent dielectric.

\section{Solvents used}

The sintered phospholipid structure was used to determine the effect of water, methanol, ethanol, acetone, isopropanol, tetrahydrofuran, acetic acid, and diethyl ether on the membrane thickness. Based on this, we will examine the changes that have been made due to different solvents and, consequently, the constant changes of the dielectric solvent, and the theory of mosaic fluidity on the thickness of the phospholipid membrane.

\section{Water solvent}

Figure 9 shows the phospholipid membrane under the influence of a water solvent having a molar mass of 18.01 $\mathrm{g} / \mathrm{mol}$ and a density of $993 \mathrm{~kg} / \mathrm{m}^{3}$ and a bipolar layer of $1.85 \mathrm{D}$. In this solvent, the total thickness of the phospholipid membrane is $7.861 \mathrm{~nm}$, which is 2.208 $\mathrm{nm}$ for outer membrane thickness; the middle membrane thickness is $3.436 \mathrm{~nm}$, and the internal membrane thickness is $2.217 \mathrm{~nm}$, which is the change relative to other solvents which are desirable due to the difference in the solvent dielectric constant.

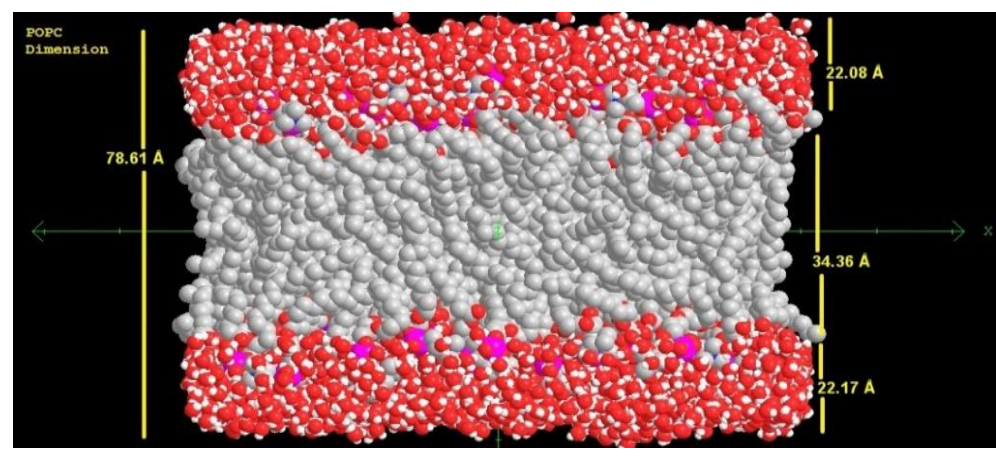

Figure 9. Solvent: Water

\section{Methanol solvent}

Figure 10 shows the phospholipid membrane under the influence of a methanol solvent with a molecular weight of $32.04 \mathrm{~g} / \mathrm{mol}$ and a density of $792 \mathrm{~kg} / \mathrm{m}^{3}$ and a dipole moment of 1.70D. In this solvent, the total thickness of the phospholipid membrane is 7.841 $\mathrm{nm}$, which is, for outer membrane thickness, equal to $2.200 \mathrm{~nm}$, the middle membrane thickness is $3.431 \mathrm{~nm}$, and the internal membrane thickness is equal to $2.210 \mathrm{~nm}$, which is the change relative to other solvents that are desirable due to the difference in the solvent dielectric constant. Alcohols are both polar and hydrogen-bonded.

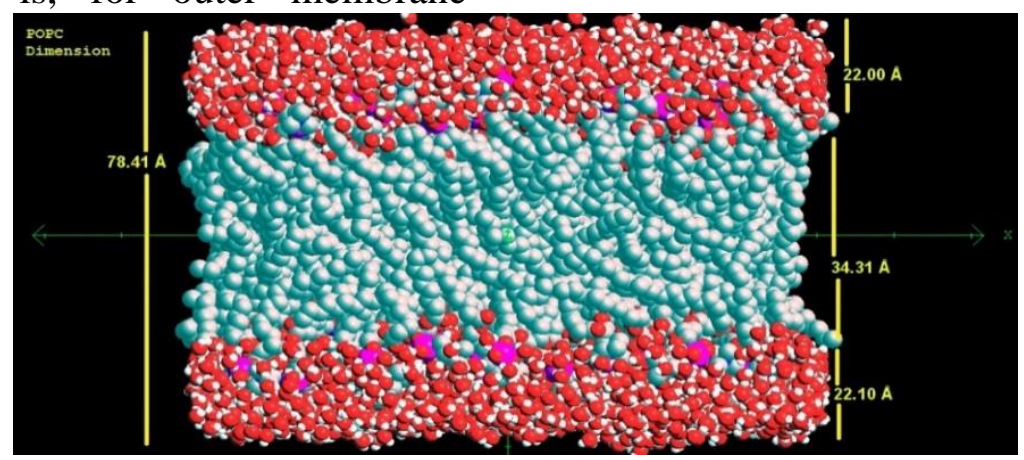

Figure 10. Solvent: methanol 


\section{Ethanol solvent}

Figure 11 shows the phospholipid membrane by the ethanol solvent with a molar mass of $46.06 \mathrm{~g} / \mathrm{mol}$ and a density of $789 \mathrm{~kg} / \mathrm{m}^{3}$ and a dipole moment of 1.69D. In this solvent, the total thickness of the phospholipid membrane is 7.830 $\mathrm{nm}$, which is $2.196 \mathrm{~nm}$ for outer membrane thickness, the middle membrane thickness is $3.429 \mathrm{~nm}$, and the internal membrane thickness is 2.205 $\mathrm{nm}$, which is the change relative to other solvents that are desirable due to the difference in the solvent dielectric constant. Alcohols are both polar and hydrogen-bonded.

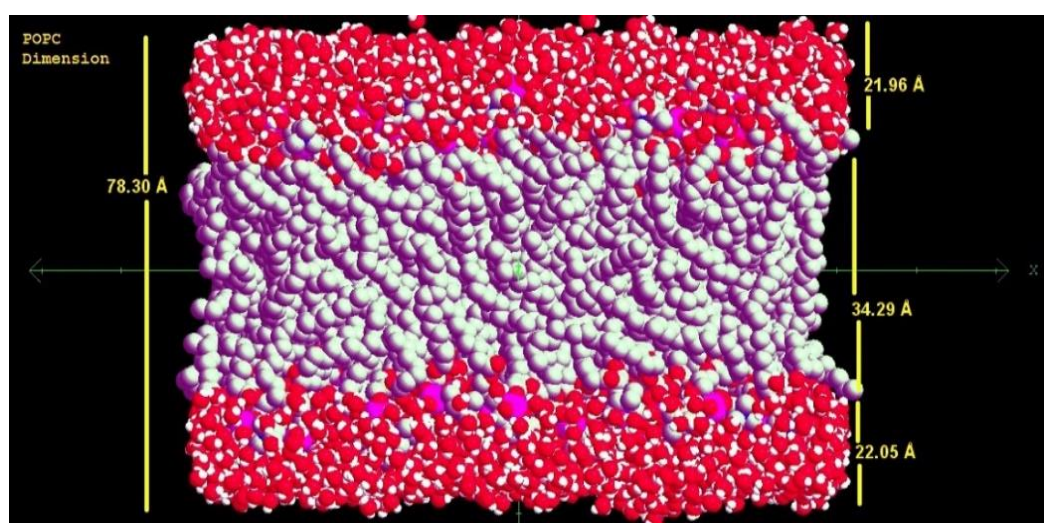

Figure 11. Solvent: ethanol

\section{Acetone solvent}

Figure 12 shows the phospholipid membrane under acetone solvent with a molecular weight of $58.08 \mathrm{~g} / \mathrm{mol}$ and a density of $791 \mathrm{~kg} / \mathrm{m}^{3}$ and a dipole moment of 2.91D. In this solvent, the total thickness of the phospholipid membrane is $7.794 \mathrm{~nm}$, which is, for outer membrane thickness, equal to
$2.189 \mathrm{~nm}$, the middle membrane thickness is $3.412 \mathrm{~nm}$, and the internal membrane thickness is $2.193 \mathrm{~nm}$, which is the change relative to other solvents that are desirable due to the difference in the solvent dielectric constant. This solvent is also the same as water, methanol, ethanol, and isopropyl alcohol.

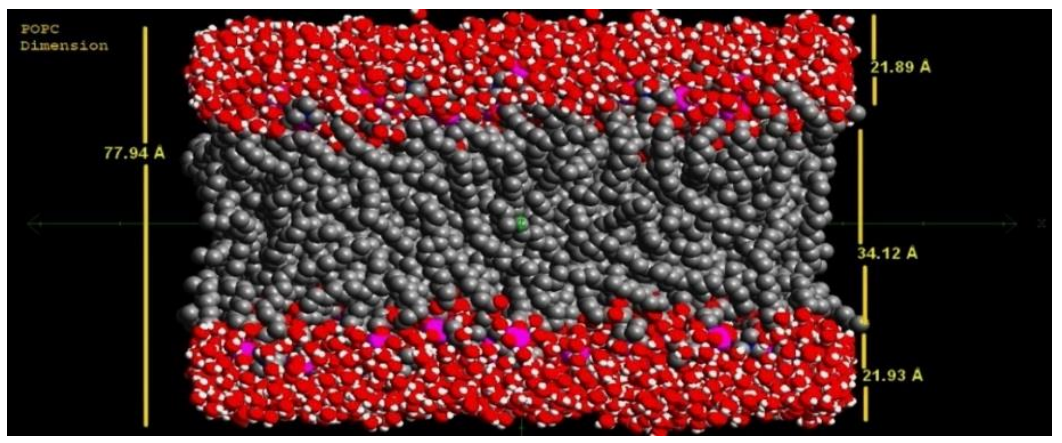

Figure 12. Solvent: acetone

\section{Isopropanol solvent}

Figure 13 shows the phospholipid membrane by the isopropanol solvent with a molecular weight of $60.10 \mathrm{~g} / \mathrm{mol}$ and a density of $786 \mathrm{~kg} / \mathrm{m}^{3}$ and a dipole moment of $1.68 \mathrm{D}$. In this solvent, the total thickness of the phospholipid membrane is $7.771 \mathrm{~nm}$, which is, for outer membrane thickness, equal to $2.187 \mathrm{~nm}$, the middle membrane thickness is $3.396 \mathrm{~nm}$, and the internal membrane thickness is equal to 2.188 $\mathrm{nm}$, which is the change relative to other solvents that are desirable due to the 
difference in the solvent dielectric water, methanol, ethanol, and acetone constant. This solvent is also the same as polar.

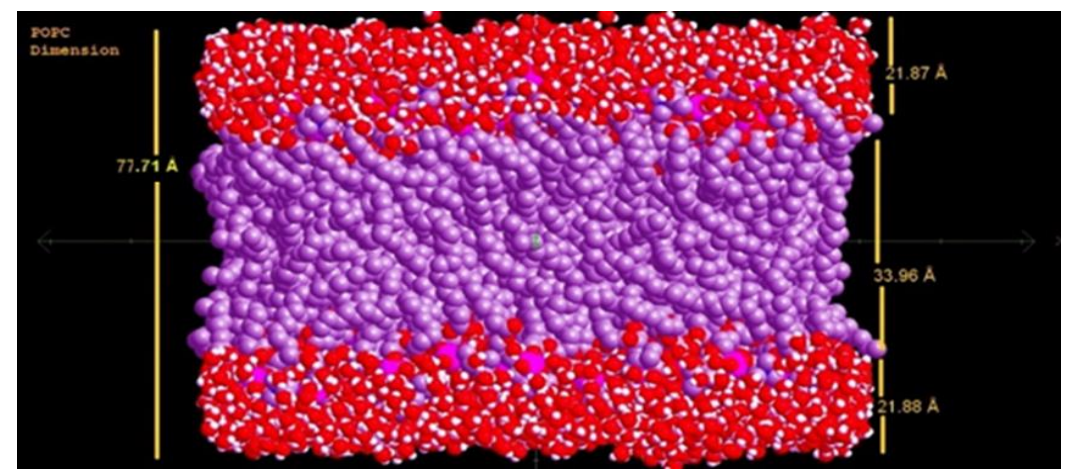

Figure 13. Solvent: isopropanol

\section{Tetrahydrofuran solvent}

Figure 14 shows the phospholipid membrane under the influence of a tetrahydrofuran solvent with a mass of $72.11 \mathrm{~g} / \mathrm{mol}$ and a density of $889 \mathrm{~kg} / \mathrm{m}^{3}$ and a dipole moment of $1.75 \mathrm{D}$. In this solvent, the total thickness of the phospholipid membrane is $7.749 \mathrm{~nm}$, which is, respectively, for the width of the layer. The outer is equal to $2.187 \mathrm{~nm}$, the middle membrane thickness is 3.373 $\mathrm{nm}$, and the internal membrane thickness is $2.189 \mathrm{~nm}$, which is the change from the previous solvent due to the difference in solvent polarity and dielectric constant. This solvent has no effect on the thickness of the outer and inner membrane than the isopropanol solvent. Although there is a significant difference between the dielectric constant of the two solvents, this solvent is non-polar, and this property can neutralize the effect of the dielectric constant to the degree that the thickness of these two layers shows no discrepancy relative to the isopropanol solvent.

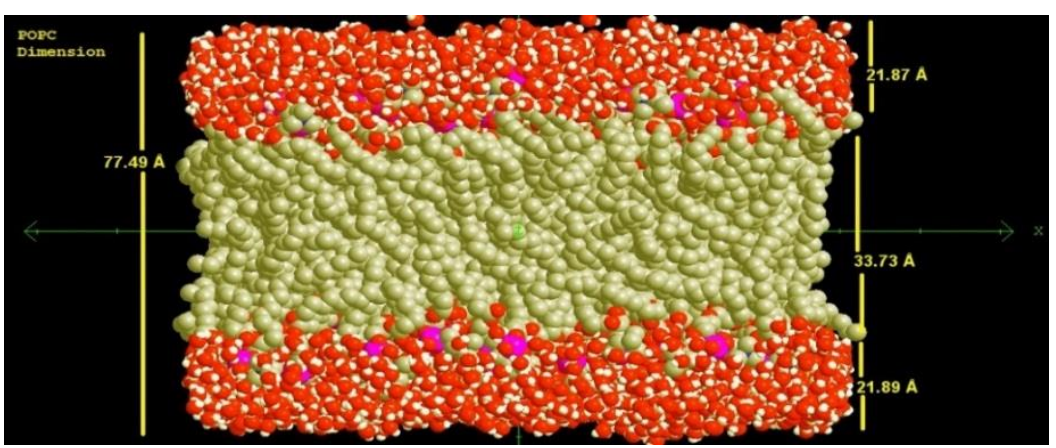

Figure 14. Solvent: tetrahydrofuran

\section{Acetic acid solvent}

Figure 15 shows the phospholipid membrane of acetic acid solvent with a molar mass of $60.05 \mathrm{~g} / \mathrm{mol}$ and a density of $1049 \mathrm{~kg} / \mathrm{m}^{3}$ and a dipole moment of 1.74D. In this solvent, the total thickness of the phospholipid membrane is 7.712 $\mathrm{nm}$, which, for outer membrane thickness, is equal to $2.169 \mathrm{~nm}$, the middle membrane thickness is $3.372 \mathrm{~nm}$, and the internal membrane thickness is equal to $2.171 \mathrm{~nm}$, which is the change relative to other solvents that are desirable due to the difference in the solvent dielectric constant. 


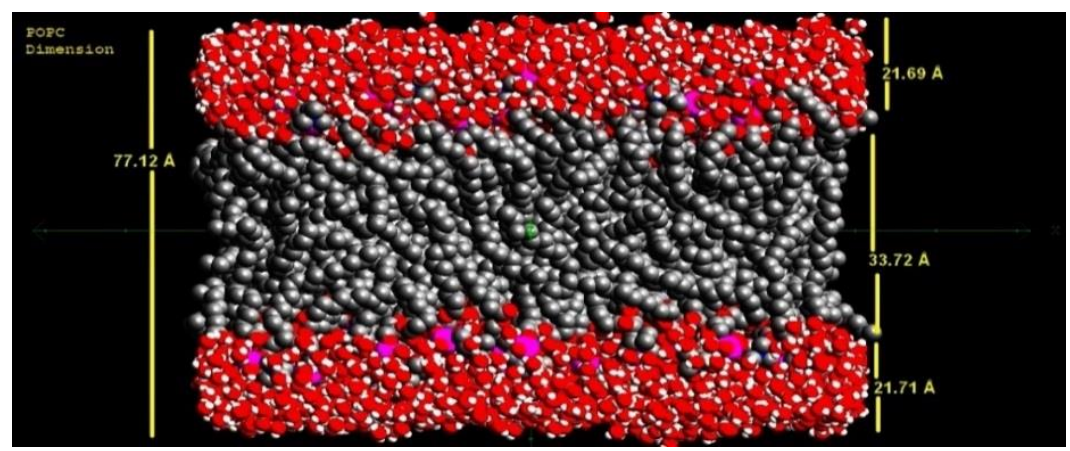

Figure 15. Solvent: acetic acid

\section{Diethyl ether solvent}

Figure 16 shows the phospholipid membrane under the influence of a solution of ethyl ether with a molar mass of $74.12 \mathrm{~g} / \mathrm{mol}$ and a density of 713 $\mathrm{kg} / \mathrm{m}^{3}$ and a dipole moment of $1.15 \mathrm{D}$. In this solvent, the total thickness of the phospholipid membrane is $7.695 \mathrm{~nm}$, which, for outer membrane thickness is about $2.160 \mathrm{~nm}$, the middle membrane thickness is $3.369 \mathrm{~nm}$, and the internal membrane thickness is $2.166 \mathrm{~nm}$, which is the change relative to other solvents that are desirable due to the difference in the solvent dielectric constant. This solvent is a very weak polar solvent and has a very low dielectric constant compared to other solutions for the thinnest membrane.

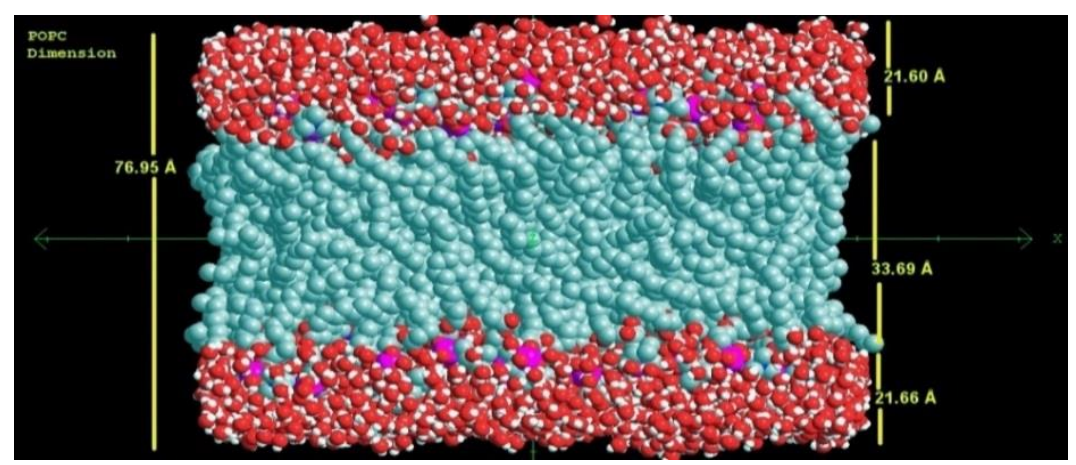

Figure 16. Solvent: diethyl ether

\section{Results and discussion}

Obviously, with the change of solvent, the dielectric constant changes too and has different effects on the thickness of the phospholipid membrane and its outer, middle, and inner layers. By comparing these changes, as shown in Tables 1 to 4 and Figures 17 to 20, changes in the thickness of the inner layers in the vicinity of different solvents with the shift from this effect are consistent with the total width of the phospholipid membrane. It seems to be the determining factor in changing the thickness of the membrane against different solvents of the phospholipid inner layer. Between all solutions, water has the highest dielectric constant. The more dielectric constant, the less gravity of the ions is, so they can dissolve more effectively and transport the compounds and it can penetrate the membrane more easily. 
Table 1. Used solvents and outer layer thickness

\begin{tabular}{|c|c|c|c|}
\hline Solvent & $\begin{array}{c}\text { Dielectric } \\
\text { constant }(\varepsilon)\end{array}$ & $\begin{array}{l}\text { Reverse dielectric } \\
\text { constant } 1 / \varepsilon(E+02)\end{array}$ & $\begin{array}{c}\text { Outer layer } \\
\text { thickness (Å) }\end{array}$ \\
\hline Water & 78.30 & 1.28 & 22.08 \\
\hline Methanol & 32.60 & 3.07 & 22.00 \\
\hline Ethanol & 24.50 & 4.08 & 21.96 \\
\hline Acetone & 20.60 & 4.85 & 21.89 \\
\hline Isopropanol & 20.33 & 4.92 & 21.87 \\
\hline Tetrahydrofuran & 7.60 & 13.16 & 21.87 \\
\hline Acetic Acid & 6.20 & 16.13 & 21.69 \\
\hline Diethyl Ether & 4.20 & 23.81 & 21.60 \\
\hline
\end{tabular}

Table 2. Used solvents and intermediate layer thickness

\begin{tabular}{|c|c|c|c|}
\hline Solvent & $\begin{array}{c}\text { Dielectric } \\
\text { constant }(\varepsilon)\end{array}$ & $\begin{array}{c}\text { Reverse dielectric } \\
\text { constant } 1 / \varepsilon(E+02)\end{array}$ & $\begin{array}{c}\text { Intermediate layer } \\
\text { thickness }(\hat{\AA})\end{array}$ \\
\hline Water & 78.30 & 1.28 & 34.36 \\
\hline Methanol & 32.60 & 3.07 & 34.31 \\
\hline Ethanol & 24.50 & 4.08 & 34.29 \\
\hline Acetone & 20.60 & 4.85 & 34.12 \\
\hline Isopropanol & 20.33 & 4.92 & 33.96 \\
\hline Tetrahydrofuran & 7.60 & 13.16 & 33.73 \\
\hline Acetic Acid & 6.20 & 16.13 & 33.72 \\
\hline Diethyl Ether & 4.20 & 23.81 & 33.69 \\
\hline
\end{tabular}

Table 3. The solvents used and layer thickness internal

\begin{tabular}{|c|c|c|c|}
\hline Solvent & $\begin{array}{c}\text { Dielectric } \\
\text { constant }(\varepsilon)\end{array}$ & $\begin{array}{l}\text { Reverse dielectric } \\
\text { constant } 1 / \varepsilon(E+02)\end{array}$ & $\begin{array}{c}\text { Layer thickness } \\
\text { internal (Å) }\end{array}$ \\
\hline Water & 78.30 & 1.28 & 22.17 \\
\hline Methanol & 32.60 & 3.07 & 22.10 \\
\hline Ethanol & 24.50 & 4.08 & 22.05 \\
\hline Acetone & 20.60 & 4.85 & 21.93 \\
\hline Isopropanol & 20.33 & 4.92 & 21.88 \\
\hline Tetrahydrofuran & 7.60 & 13.16 & 21.89 \\
\hline Acetic Acid & 6.20 & 16.13 & 21.71 \\
\hline Diethyl Ether & 4.20 & 23.81 & 21.66 \\
\hline
\end{tabular}

Table 4. The solvents used and membrane thickness

\begin{tabular}{|c|c|c|c|}
\hline Solvent & $\begin{array}{c}\text { Dielectric } \\
\text { constant }(\varepsilon)\end{array}$ & $\begin{array}{l}\text { Reverse dielectric } \\
\text { constant } 1 / \varepsilon(E+02)\end{array}$ & 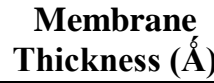 \\
\hline Water & 78.30 & 1.28 & 78.61 \\
\hline Methanol & 32.60 & 3.07 & 78.41 \\
\hline Ethanol & 24.50 & 4.08 & 78.30 \\
\hline Acetone & 20.60 & 4.85 & 77.94 \\
\hline Isopropanol & 20.33 & 4.92 & 77.71 \\
\hline Tetrahydrofuran & 7.60 & 13.16 & 77.49 \\
\hline Acetic Acid & 6.20 & 16.13 & 77.12 \\
\hline Diethyl Ether & 4.20 & 23.81 & 76.95 \\
\hline
\end{tabular}




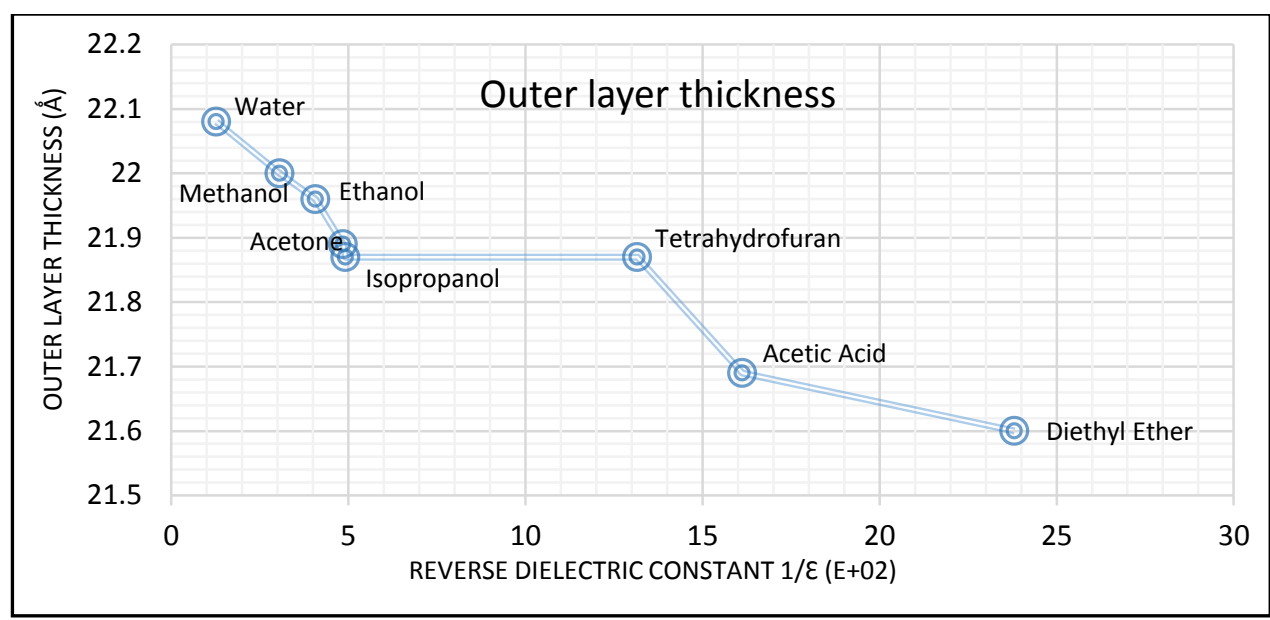

Figure 17. The solvents used and outer layer thicknes

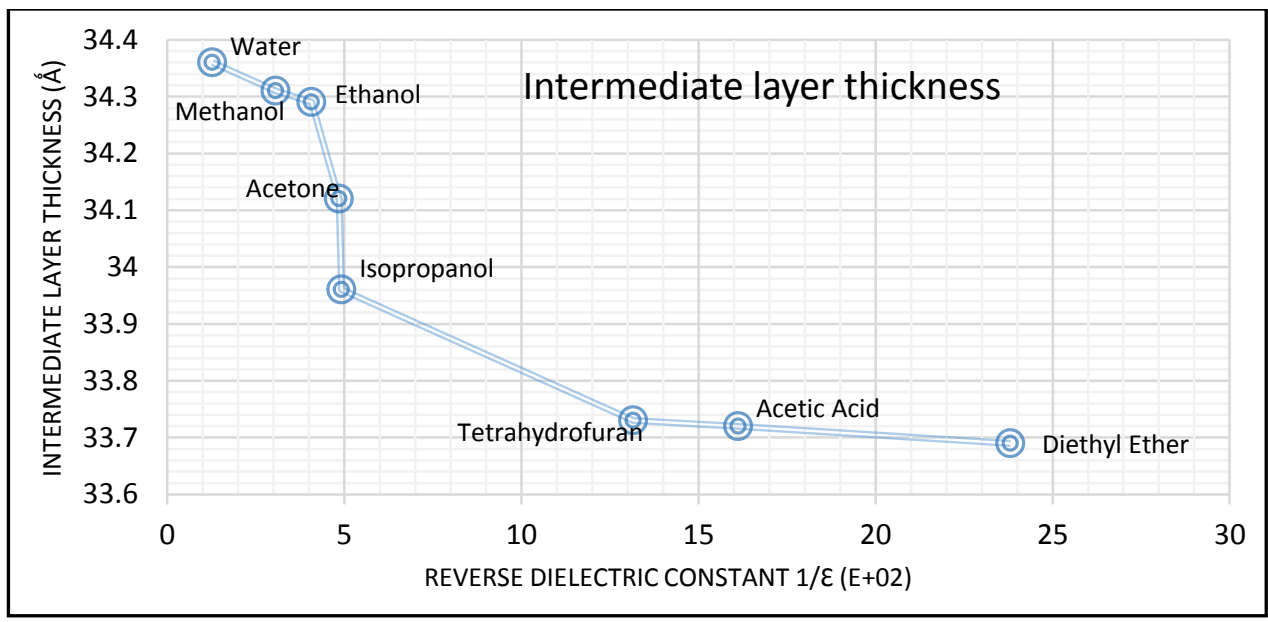

Figure 18. The solvents used and intermediate layer thickness

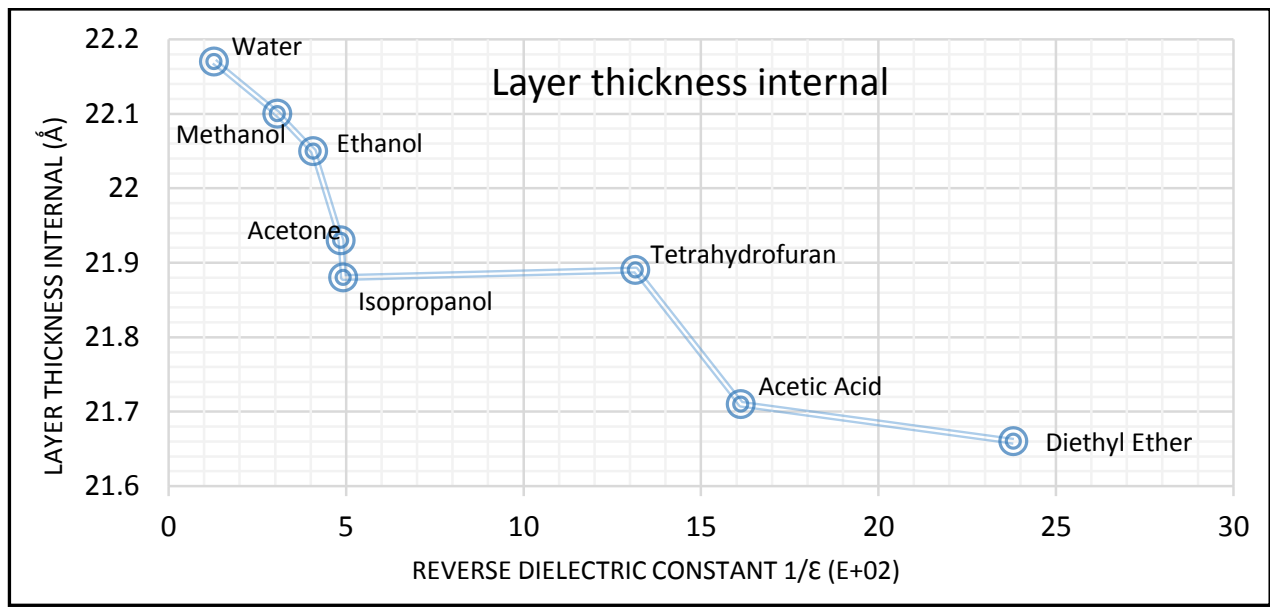

Figure 19. The solvents used and layer thickness internal 


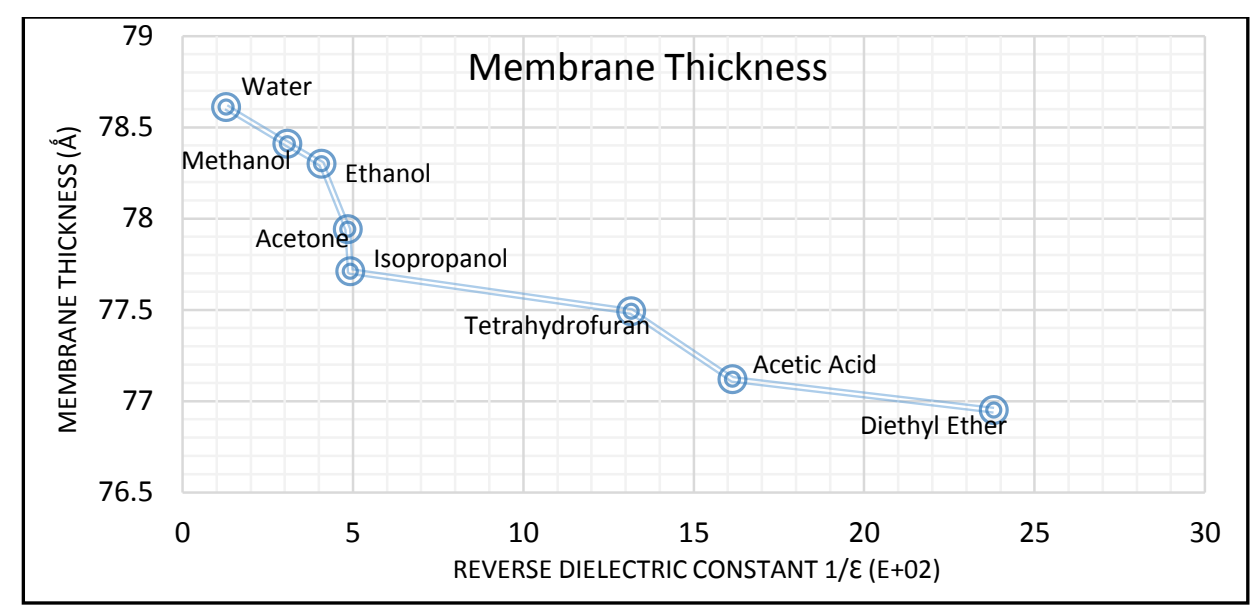

Figure 20. The solvents used and membrane thickness

Thermodynamic studies of solvent effects on membrane phospholipids

In this section, calculations are based on quantum mechanics using the M062X/6$31 \mathrm{G}$ method. According to Table 5, thermodynamic functions such as $\Delta \mathrm{G}$, $\Delta \mathrm{K}$, and $\Delta \mathrm{S}$ were calculated for phospholipid in water solvent using the thermodynamic and frequency studies in the aqueous solution. It is noteworthy that the dimensions of the solvent environment are equal to $15 \dot{A}$ based on the three components $\mathrm{x}, \mathrm{y}, \mathrm{z}$.

Table 5. Thermodynamic functions calculated at the level of M062X/6-31g for solvent effects

\begin{tabular}{|c|c|c|c|c|}
\hline $\begin{array}{c}\text { Thermodynamic } \\
\text { Functions }\end{array}$ & $\Delta G(\mathrm{cal} / \mathrm{mol})$ & $\Delta K(\mathrm{cal} / \mathrm{mol})$ & $\Delta \mathrm{E}(\mathrm{cal} / \mathrm{mol})$ & $\Delta S$ (cal/K.mol) \\
\hline Water Solvent & $\begin{array}{c}-99.0433 \\
(\mathrm{E}+01)\end{array}$ & $\begin{array}{c}314.4052267 \\
(\mathrm{E}+01)\end{array}$ & $\begin{array}{c}-413.449 \\
(\mathrm{E}+01)\end{array}$ & $\begin{array}{c}211.29391 \\
(\mathrm{E}-03)\end{array}$ \\
\hline
\end{tabular}

These functions indicate that the system in question is thermodynamically stable and that the solvent in question stabilizes the system, and this process is a spontaneous event. The more kinetic energy of the structure is less, and its potential energy higher, the structure will be more active.

\section{Thinning contribution thickness of the membrane for each solvent}

The thinning contribution of the thickness of the membrane was calculated for the above solutions relative to the water solvent. As expected, according to Tables 6 and 7, respectively, from methanol solvent to diethyl ether solvent with a reduction of the solvent dielectric constant, greater solvent thinning contribution and the phospholipid membrane is thinner.

Table 6. Used solvents and percentage of thickness relative to water solvent

\begin{tabular}{|c|c|c|c|c|c|c|c|c|}
\hline Solvent & $\begin{array}{c}\text { Layer } \\
\text { thickness } \\
\text { internal } \\
\text { (Á) }\end{array}$ & $\begin{array}{c}\text { Layer } \\
\text { percentag } \\
\mathrm{e} \\
\text { domestic }\end{array}$ & $\begin{array}{c}\text { Intermediat } \\
\text { e layer } \\
\text { thickness } \\
\text { (Á) }\end{array}$ & $\begin{array}{c}\text { Percentag } \\
\text { e layer } \\
\text { percentag } \\
\text { e }\end{array}$ & $\begin{array}{c}\text { Outer } \\
\text { layer } \\
\text { thickness } \\
(\AA ̊)\end{array}$ & $\begin{array}{c}\text { Percentag } \\
\text { e of the } \\
\text { outer } \\
\text { layer }\end{array}$ & $\begin{array}{c}\text { Membran } \\
\text { e } \\
\text { Thickness } \\
\text { (Á) }\end{array}$ & $\begin{array}{c}\text { Percentag } \\
\text { e of } \\
\text { membran } \\
\text { e } \\
\text { thickness }\end{array}$ \\
\hline Water & 22.17 & 100 & 34.36 & 100 & 22.08 & 100 & 78.61 & 100 \\
\hline Methanol & 22.10 & 99.68 & 34.31 & 99.85 & 22.00 & 99.64 & 78.41 & 99.74 \\
\hline Ethanol & 22.05 & 99.46 & 34.29 & 99.80 & 21.96 & 99.46 & 78.30 & 99.60 \\
\hline Acetone & 21.93 & 98.92 & 34.12 & 99.30 & 21.89 & 99.14 & 77.94 & 99.15 \\
\hline Isopropanol & 21.88 & 98.69 & 33.96 & 98.83 & 21.87 & 99.05 & 77.71 & 98.85 \\
\hline $\begin{array}{c}\text { Tetrahydrofu } \\
\text { ran }\end{array}$ & 21.89 & 98.74 & 33.73 & 98.17 & 21.87 & 99.05 & 77.49 & 98.57 \\
\hline Acetic Acid & 21.71 & 97.92 & 33.72 & 98.14 & 21.69 & 98.23 & 77.12 & 98.10 \\
\hline Diethyl Ether & 21.66 & 97.70 & 33.69 & 98.05 & 21.60 & 97.83 & 76.95 & 97.89 \\
\hline
\end{tabular}


Table 7. Used solvents and percentage of thinning the membrane

\begin{tabular}{|c|c|c|c|c|}
\hline Solvent & $\begin{array}{c}\text { Dielectric } \\
\text { constant }(\varepsilon)\end{array}$ & $\begin{array}{c}\text { Reverse dielectric } \\
\text { constant } 1 / \varepsilon(E+02)\end{array}$ & $\begin{array}{c}\text { Membrane } \\
\text { Thickness (Å) }\end{array}$ & $\begin{array}{c}\text { Thinning to } \\
\text { water solvent }\end{array}$ \\
\hline Water & 78.30 & 1.28 & 78.61 & $\% 0.00$ \\
\hline Methanol & 32.60 & 3.07 & 78.41 & $\% 0.25$ \\
\hline Ethanol & 24.50 & 4.08 & 78.30 & $\% 0.39$ \\
\hline Acetone & 20.60 & 4.85 & 77.94 & $\% 0.85$ \\
\hline Isopropanol & 20.33 & 4.92 & 77.71 & $\% 1.14$ \\
\hline Tetrahydrofuran & 7.60 & 13.16 & 77.49 & $\% 1.42$ \\
\hline Acetic Acid & 6.20 & 16.13 & 77.12 & $\% 1.89$ \\
\hline Diethyl Ether & 4.20 & 23.81 & 76.95 & $\% 2.11$ \\
\hline
\end{tabular}

Membrane thickness and normal and abnormal state

Figures 21 and 22 show normal shape, and Figures 23 and 24 show abnormal state and membrane thickness. Regular forms associated with water solvent have been obtained, and irregular forms have accomplished with a solvent of diethyl ether.

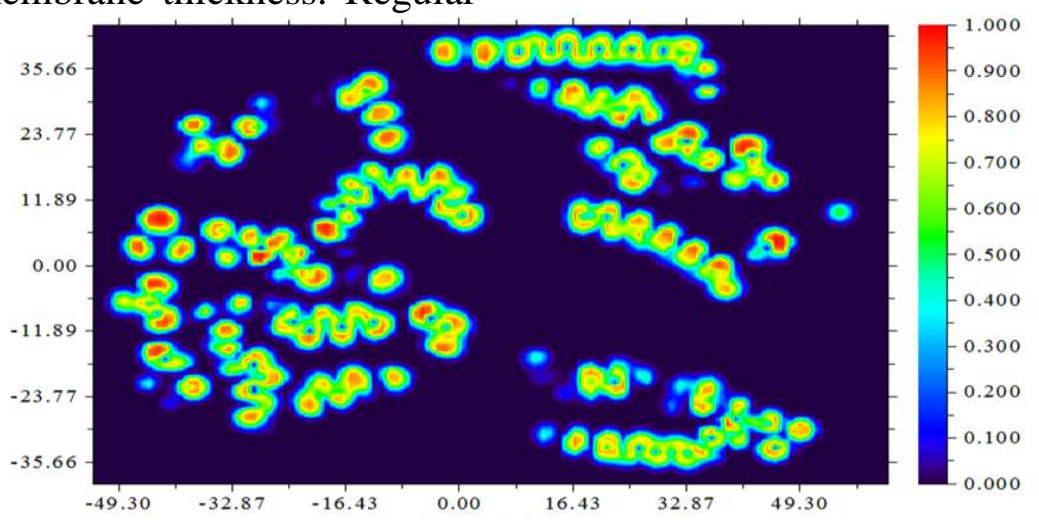

Figure 21. The color map of density state for POPC

In Figure 21, the dark and black surfaces are absorbent and pass through and transmit the material through the cell membrane, and the bright and white points prevent the absorption, transmission and transport. Therefore, as is evident, the areas and portions of passage and communication are more, and there are paths and game tunnels available to absorb and transport the material from the membrane.

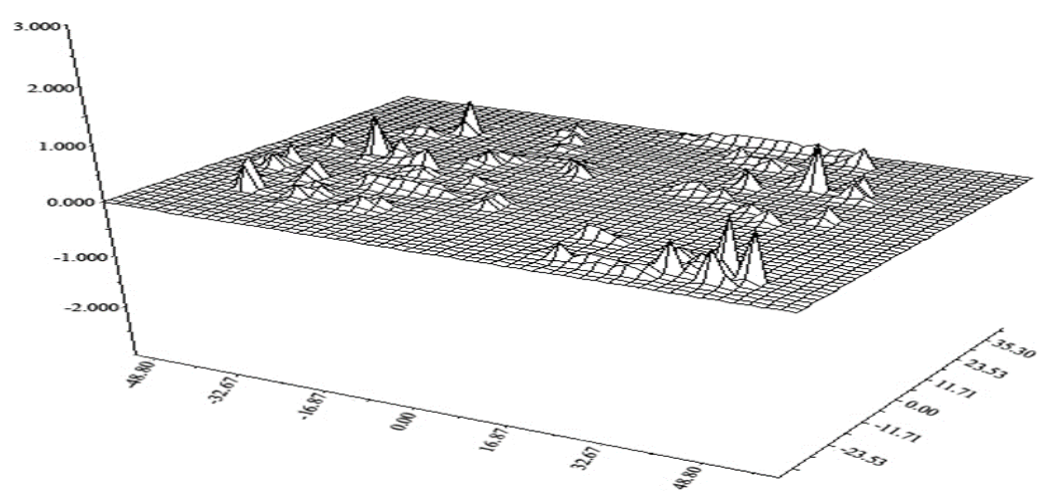

Figure 22. The vector map with a rugged design for POPC.

As noted, the open paths and tunnels in Figure 22 are entirely recognizable and observable. As shown in Figures 23 and 24, there are no free and 
unobstructed tunnels in Figures 21 and 22 , and there is no clear pathway for passing through and through the cell membrane.

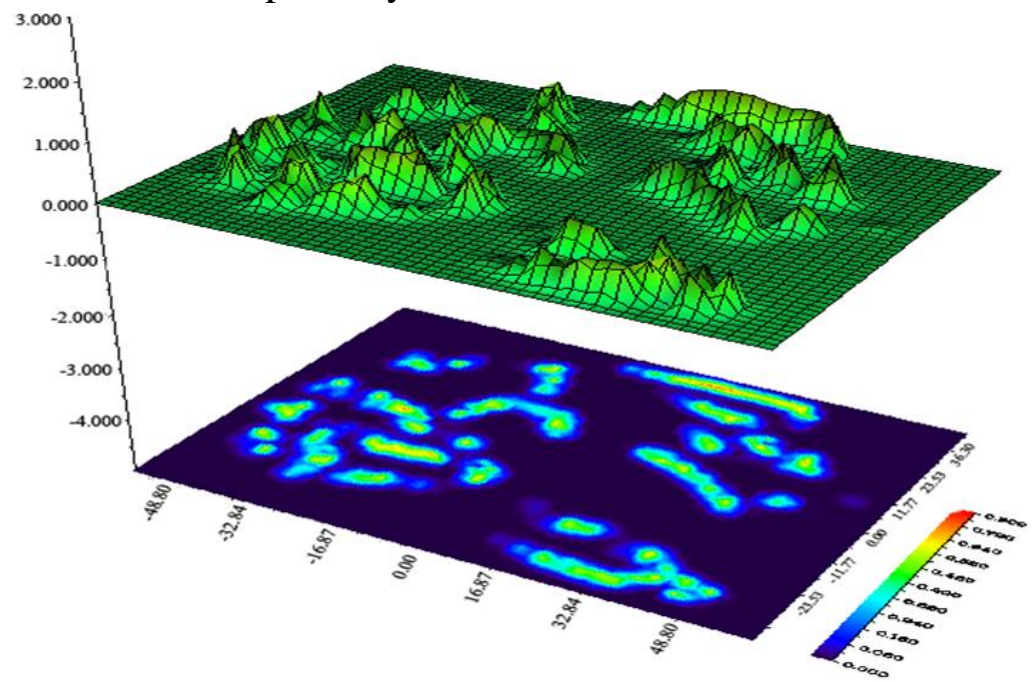

Figure 23. The electron density with a projection for POPC

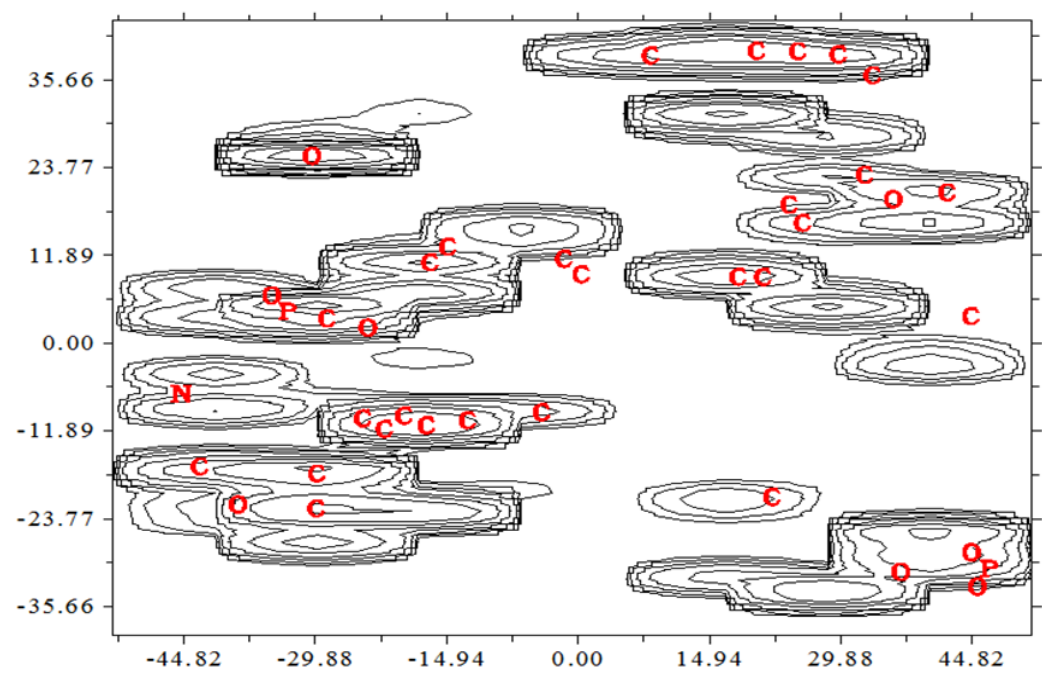

Figure 24. The topology map for POPC

\section{Conclusion}

According to Figures 9-20, it is concluded that the water least and diethyl ether cause the most damage to the membrane. Now, with a focus on membrane thickness, for the first time, a parameter can be introduced as a thinner membrane thickness factor. Considering the new technologies of biotechnology and pharmaceuticals by formulating solvents about the thickness of the membrane and the parameter of thinning, this factor can be used for drugs that directly relate to different cells of the physiology of the body, and a series of medications. Thermodynamic functions indicate that the system is stable in terms of thermodynamics and stabilizes the desired solution without distorting structural cohesion. For this reason, this factor can play an essential role in the pharmaceutical industry. Investigation of the solvent effects on the phospholipid structure led to changes in the structure thickness that plays the most important role in the dynamics of phospholipid in the membrane. Given the interplay of this factor, there is the talk of transfer and exchange on these membranes, and if factors similar to human genetic 
structural factors are considered for exchange, they can be very useful and rapid transmitters deliver medicine to target cells. Accordingly, in the case of pharmacy and drug delivery, taking into account, the proper solvent increases the reactivity and solubility of the drug, thus reducing the dose of the medicine and preventing damage to other tissues in the body. On the other hand, reducing the dosage of the drug leads to a lack of resistance to the drugs.

\section{Acknowledgments}

We express appreciation to Professor Majid Monajjemi in Islamic Azad University, Department of chemical engineering, Central Tehran Branch, for his guidance and assistance.

\section{Reference}

[1] J. Leszczynski, A. KaczmarekKedziera, T. Puzyn, M.G. Papadopoulos, H. Reis, M.K.K. Shukla, (Eds.), Handbook of Computational Chemistry, Springer, Switzerland, 2017.

[2] S. Baoukina, D. Rozmanov, D.P. Tieleman, Biophys. J., 2017, 113, 27502761.

[3] T. Róga, I. Vattulainenab, Chem. Phys. Lipids., 2014, 184, 82-104.

[4] M. Soleiman-Beigi, Z. Arzehgar, Synlett., 2018, 29, 986-992.

[5] M. Soleiman-Beigi, Z. Arzehgar, Monatsh Chem., 2016, 147, 1759-1763.

[6] W.F. DrewBennettD, P. Tieleman, BBA-Biomembranes., 2013, 1828, 17651776.

[7] E. Niebur, K. Mind, Scholarpedia., 2008, 3, 7166.

[8] A. Elsagh, H.R. Jalilian, E. Kianpour, H.S. Gazi Mokri, M. Rajabzadeh, M.S. Moosavi, F. Ghaemi Amiri, M. Monajjemi, J. Comput. Theor. Nanosci., 2015, 12, 4211-4218.

[9] W. Shinoda, BBA-Biomembranes., 2016, 1858, 2254-2265.

[10] J.G. Almeida, A.J. Preto, P.I. Koukos, A.M.J.J. Bonvin, I.S. Moreira,
BBA-Biomembranes., 2017, 1859, 20212039.

[11] M. Hotokka, E.J. Brändas, J. Maruani, G. Delgado-Barrio, (Eds.). Advances in Quantum Methods and Applications in Chemistry, Physics, and Biology, Springer, Switzerland, 2013.

[12] M.P. Haataja, Biophys. J., 2017, 112, 655-662.

[13] N. Ahmadinejad, M.T. Trai, Chem. Methodol., 2019, 3, 55-66.

[14] W. Saidi, T. Abram, L. Bejjit, M. Bouachrine, Chem. Methodol., 2018, 2, 247-259.

[15] A. Ramazani, M. Sheikhib, H. Yahyaeic, Chem. Methodol., 2017, 1, 2848.

[16] L. Shiri, D. Sheikh, S. Janinia, M. Sheikhi, Chem. Methodol., 2019, 3, 392407.

[17] A. Mirzaie, J. Med. Chem. Sci., 2018, 1, 31-32.

[18] M. Nabati, V. Bodaghi-Namileh, S. Sarshar, Prog. Chem. Biochem. Res., 2019, 2, 108-119.

[19] (a) P. Fromme, A. Sali, Curr. Opin. Struct. Biol., 2016, 40, 9-11; (b) K.K. Alisher, T.S. Khamza, Y.S. Ikbol, Prog. Chem. Biochem. Res., 2019, 2, 1-5.

[20] A. Elsagh, K. Zare, NBO, NQR, and NMR Investigation of Calix-Aren Family in Point View of Nano-drug Delivery: A Monte Carlo and QM/MM Study, 3rd International Conference on Computation for Science and Technology, Bali, Indonesia, September, $23^{\text {rd }}-25^{\text {th }}, 2014$.

[21] A.P. Lyubartsev, A.L. Rabinovich, BBA-Biomembranes., 2016, 1858, 24832497.

[22] K. Simons, BBA-Biomembranes., 2016, 1858, 2569-2572.

[23] A. Elsagh, H.R. Jalilian, A.R. Ilkhani, Orient. J. Chem., 2015, 31, 223229.

[24] W. Kulig, M. PasenkiewiczGierula, T. Róga, J. Data. Brief., 2015, 5 , 333-336. 
[25] A. Anishkin, S. Sukharev, M. Colombini, Biophys. J., 2006, 90, 24142426.

[26] A. Elsagh, K. Zare, M. Monajjemi, Orient. J. Chem., 2016, 32, 2585-2598.
[27] A. Elsagh, K. Zare, M. Monajjemi, Ukrainian. J. Ecology, 2018, 8, 165-173. [28] K.I. Ramachandran, G. Deepa, K. Namboori, Computational Chemistry, and Molecular Modeling, SpringerVerlag Berlin Heidelberg, 2008.

How to cite this manuscript: Akbar Elsagh. Quantum study of solvent effect with POPC phospholipid bilayers in a cell membrane and its impact on active and targeted drug delivery. Eurasian Chemical Communications, 2020, 2(4), 440-455. 